\title{
Expression patterns of the tumor suppressor PDCD4 and correlation with $\beta$-catenin expression in gastric cancers
}

\author{
TAKASHI KAKIMOTO ${ }^{1,5}$, RYOSUKE SHIRAISHI ${ }^{1}$, RYUICHI IWAKIRI $^{1}$, KAZUMA FUJMOTO $^{1}$, \\ HIROKAZU TAKAHASHI ${ }^{1}$, HIROSHI HAMAJIMA ${ }^{1}$, TOSHIHIKO MIZUTA ${ }^{1}$, HIROYUKI IDEGUCHI ${ }^{2}$, \\ SHUJI TODA ${ }^{2}$, YOSHIHIKO KITAJIMA ${ }^{3}$, IWATA OZAKI ${ }^{1,4}$ and SACHIKO MATSUHASHI ${ }^{1}$ \\ Departments of ${ }^{1}$ Internal Medicine, ${ }^{2}$ Pathology,${ }^{3}$ Surgery, and ${ }^{4}$ Health Administration Center, \\ Faculty of Medicine, Saga University, 5-1-1 Nabeshima, Saga 849-8501, Japan
}

Received June 28, 2011; Accepted August 16, 2011

DOI: $10.3892 / o r .2011 .1450$

\begin{abstract}
The expression patterns of PDCD4, a tumor suppressor, and $\beta$-catenin were immunohistologically investigated in gastric carcinoma tissues. In normal gastric tissues, PDCD4 was strongly expressed in the cell nuclei, but weakly expressed in the cytoplasm. In gastric adenocarcinoma tissues, nuclear PDCD4 expression was decreased, while cytoplasmic PDCD4 expression was unchanged or somewhat increased. In gastric signet ring cell carcinoma tissues, PDCD4 expression patterns were different from the expression patterns of the adenocarcinoma tissues, and PDCD4 was localized in the nuclei of the carcinoma cells as a belt in the middle of the epithelial layer. The nuclear localization of PDCD4 in the adenocarcinoma tissues was correlated with the membrane localization of $\beta$-catenin, the activation of which stimulates invasion of colon cancer cells. PDCD4 expression was correlated with $\beta$-catenin expression in gastric carcinoma cell lines, but not with E-cadherin, as the binding partner in the cell membrane.
\end{abstract}

\section{Introduction}

The human programmed cell death 4 (PDCD4) gene (H731) was first isolated as an antigen gene involved in the cell cycle $(1,2)$ and mapped at 10q24 (3). Homologs in mice (MA-3/TIS) $(4,5)$, chickens $(6,7)$ and rats (DUG) $(8)$ have also been reported. The expression of the gene is modulated by many factors, including interleukins (9), retinoid (10), 12-O-tetradecanoylphorbol 13

Correspondence to: Dr Sachiko Matsuhashi, Department of Internal Medicine, Faculty of Medicine, Saga University, 5-1-1 Nabeshima, Saga 849-8501, Japan

E-mail: matsuha2@edu.cc.saga-u.ac.jp

Present address: ${ }^{5}$ Clinical Research Center, National Center for Child Health and Development (NCCHD), Tokyo, Japan

Key words: gastric carcinoma, programmed cell death 4, $\beta$-catenin acetate (TPA) $(11,12)$, transforming growth factor (TGF)- $\beta 1$ (13), growth factors $(14,15)$, topoisomerase inhibitors (5) and the transcription factor myb $(6,7)$, and is up-regulated in association with apoptosis $(4,13)$. PDCD4 expression has been shown to be suppressed in many tumor tissues, such as lung cancers (16), pancreatic cancers (17), hepatocellular carcinomas (13), colon cancers (18), skin carcinomas (15), breast cancers (19) and glioma tissues (20). The PDCD4 protein levels are often not correlated with the mRNA levels in certain tumor tissues $(16,20)$, indicating that PDCD4 expression is controlled at both the transcription and post-transcription levels. Recently, it was reported that microRNA-21 targets PDCD4/Pded4 mRNA, thereby regulating PDCD4 expression (reviewed in refs. 21 and 22).

Regarding the molecular basis, PDCD4/Pdcd4 protein possesses two MA-3 domains that are homologous to the M1 domain of eukaryotic translation initiation factor $4 \mathrm{G}$ (eIF4G), a component of the translation initiation complex eIF4F (23), and potential nuclear localization signals $(1,4)$. PDCD4/ Pdcd4 protein associates with eIF4A, which binds to eIF4G in the initiation complex eIF4F and inhibits the RNA helicase activity of eIF4A, thereby inhibiting cap-dependent translation (24-27).

In response to growth factors, PDCD4 protein was rapidly phosphorylated on $\mathrm{S}^{67}$ by the protein kinase S6K1, which is activated through the mitogen-activated Akt-mammalian target of rapamycin (mTOR) signaling pathway in cells (14). The phosphorylation of $S^{67}$ promoted the phosphorylation of $\mathrm{S}^{71}$ and $\mathrm{S}^{76}$ in the canonical $\mathrm{SCF}^{\beta T R C P}$ ubiquitin ligase-binding motif $\mathrm{D}^{70}$ SGRGDS ${ }^{76}$ of PDCD4, resulting in degradation of PDCD4 via the ubiquitin-proteasome system (14). Loss of PDCD4 may stimulate protein synthesis, and the subsequent cell growth and proliferation led to carcinogenesis of the cells (14).

Mouse Pdcd4 was shown to suppress the neoplastic transformation of JB6 mouse epidermal cells exposed to the promoter TPA (28). It was demonstrated that Pdcd4 inhibited activator protein 1 (AP-1) transactivation in mouse epidermal JB6 cells $(29,30)$, and that Pdcd4 interfered with the phosphorylation of c-Jun by Jun N-terminal kinase (JNK) (31). Ectopic expression of Pdcd4 in metastatic colon carcinoma cells suppressed invasion and inhibited the transcription of mitogen-activated 
protein kinase kinase kinase kinase 1 (MAP4K1)/hematopoietic progenitor kinase 1 , which is an upstream kinase of JNK activation (32). Suppression of MAP4K1 inhibited c-Jun phosphorylation and the consequent AP-1 transactivities led to cell proliferation and invasion. The regulation of AP-1 activities by Pdcd 4 in vivo was demonstrated by generating transgenic mice that overexpress Pdcd4 in the epidermis (33). The epidermis of the transgenic mice is resistant to TPA-induced carcinogenesis (33), and PDCD4-knockdown mice show a shorter lifespan than normal siblings, mainly because of B-cell lymphoma development (34). PDCD4 knockdown stimulated the invasion of colon tumor HT29 cells and inhibited E-cadherin expression, resulting in accumulation of active $\beta$-catenin in the nuclei and stimulation of $\beta$-catenin/T cell factor (Tcf)-dependent transcription of genes such as u-PAR and c-Myc, which activate invasion as well as AP-1-dependent transcription $(35,36)$. PDCD4 inhibited breast cancer cell migration and invasion by suppressing the expression of lysyl oxidase (LOX) mRNA (37).

In gastric cell cancer, it has been reported that PDCD4 suppression is correlated with clinicopathological parameters and the clinical prognosis (38). However, the precise function of PDCD4 in gastric cells is unclear. In this study, we immunohistochemically investigated the PDCD4 expression patterns in human stomach cancers and the correlation with $\beta$-catenin, which functions in invasion of colon cancer.

\section{Materials and methods}

Patients. From January 2003 to December 2004, 21 consecutive patients with gastric carcinoma who agreed to participate in this study were enrolled. All the patients underwent a surgical gastrectomy at Arita Kyoritsu Hospital. The study was conducted with the approval of the Ethics Committee of Arita Kyoritsu Hospital. Written informed consent was obtained from all subjects before entry into the study. The tumor stage was classified according to the TNM staging system.

Tissues and cell lines. Tumor tissue specimens were obtained from stock samples surgically obtained from the patients. Each specimen was fixed in $10 \%$ formalin, paraffin-embedded, sectioned and stained with hematoxylin-eosin for histological evaluation. Normal stomach tissues obtained during routine surgical procedures at Saga University Hospital were used as controls for biochemical analyses. The procedures were performed with informed consent at Saga University Hospital. The gastric tumor cell lines MKN1, MKN7, MKN28, MKN45, MKN74 and KATOIII were obtained from RIKEN Bioresource Center (Tsukuba, Japan) while HSC-45 and HSC-57 (39) were gifts from Dr K. Yanagihara (Department of Life Sciences, Yasuda Women's University Faculty of Pharmacy, Hiroshima, Japan). All of the cell lines were maintained in RPMI-1640 medium containing $10 \%$ FBS.

Reagents. An anti-PDCD4 antibody was prepared by immunizing rabbits with a synthetic peptide corresponding to the $\mathrm{N}$-terminal amino acid sequence (13). Anti- $\beta$-catenin, anti-Ecadherin, anti-Akt, anti-p44/42 MAP kinase and anti- $\beta$-actin antibodies were purchased from Cell Signaling Technology (Beverly, MA). An anti-PCNA antibody was obtained from Santa Cruz Biotechnology Inc. (Santa Cruz, CA).
Table I. Clinicopathological characteristics of the subjects.

$(n=21)$

\begin{tabular}{lc} 
Age & \\
Mean (range) & \\
Gender & $12(57.4 \%)$ \\
Male & \\
Tumor (T) stage & 14 \\
T1 & 2 \\
T2 & 4 \\
T3 & 1 \\
T4 & \\
Lymphoid (L) status & 11 \\
N0 & 9 \\
N1 & 1 \\
N2 & 0 \\
N3 & \\
Distant metastasis status & \\
M0 & 21 \\
M1 & 0 \\
Histological grade & \\
Adenocarcinoma & \\
Well & \\
Moderate & \\
Poor & \\
Signet ring cell carcinoma & 7 \\
\hline
\end{tabular}

Immunohistochemistry. After deparaffinization, 4- $\mu \mathrm{m}$ sections of the tumor tissues were treated with $1 \mathrm{mM}$ EDTA for $5 \mathrm{~min}$ in a pressure cooker, and then incubated with a primary antibody. The bound antibody was visualized using a Universal Envision kit with DAB as the chromogen (Dako, Glostrup, Denmark) according to the manufacturer's protocol.

Evaluation of specimens. Semiquantitative analyses of the immunohistochemical staining were performed. The expression levels of PDCD4 and/or $\beta$-catenin were evaluated on scales of one to four or five as follows: PDCD4 in the nucleus: 5 , very strong, normal cell level; 4 , frequent and strong; 3 , frequent but weak; 2, less frequent and weak; 1, negative, staining level with non-immune serum; PDCD4 in the cytoplasm: 4 , strong; 3 , moderate; 2 , weak; 1 , negative, staining level with non-immune serum; expression of $\beta$-catenin: 4 , strong; 3 , moderate; 2 , weak; 1 , negative, staining level with non-immune serum. All the specimens were evaluated by an experienced pathologist (S.T.) who was unaware of the clinical conditions of the patients.

Western blotting. Cell extracts were prepared by sonication in an SDS buffer (2\% SDS, $0.05 \mathrm{M}$ Tris- $\mathrm{HCl}, \mathrm{pH} 6.8,1 \mathrm{mM}$ PMSF) followed by centrifugation at $10,000 \mathrm{x}$ g for $10 \mathrm{~min}$. The normal stomach tissue was homogenized in the SDS buffer using a Potter homogenizer and centrifuged at $10,000 \mathrm{x} g$ 
Table II. Immunological staining patterns of gastric adenocarcinoma.

\begin{tabular}{|c|c|c|c|c|c|c|}
\hline \multirow[b]{2}{*}{ No. } & \multicolumn{2}{|c|}{ PDCD4 } & \multicolumn{3}{|c|}{$\beta$-catenin } & \multirow[b]{2}{*}{ Differentiation } \\
\hline & Nucleus & Cytoplasm & Cytoplasm & Nucleus & Membrane & \\
\hline Control & 5 & 2 & 2 & 1 & 4 & - \\
\hline 1 & 4 & 3 & 3 & 1 & 3 & Well \\
\hline 2 & 3 & 2 & 3 & 1 & 2 & Well \\
\hline 3 & 2 & 4 & 3 & 3 & 1 & Well \\
\hline 4 & 2 & 2 & 3 & 3 & 1 & Well \\
\hline 5 & 2 & 4 & 1 & 1 & 1 & Well \\
\hline 6 & 3 & 4 & 3 & 1 & 3 & Well \\
\hline 7 & 1 & 1 & 3 & 1 & 3 & Well \\
\hline 8 & 3 & 4 & 2 & 3 & 1 & Moderate \\
\hline 9 & 1 & 3 & 3 & 3 & 1 & Moderate \\
\hline 10 & 2 & 2 & 2 & 1 & 2 & Moderate \\
\hline 11 & 1 & 1 & 1 & 1 & 1 & Moderate \\
\hline 12 & 2 & 3 & 2 & 1 & 1 & Moderate \\
\hline 13 & 3 & 4 & 3 & 1 & 2 & Poor \\
\hline 14 & 2 & 4 & 1 & 1 & 1 & Poor \\
\hline 15 & 1 & 3 & 2 & 1 & 1 & Poor \\
\hline 16 & 1 & 2 & 2 & 1 & 1 & Poor \\
\hline 17 & 3 & 4 & 3 & 1 & 2 & Poor \\
\hline 18 & 1 & 2 & 2 & 1 & 1 & Poor \\
\hline 19 & 1 & 2 & 1 & 1 & 1 & Poor \\
\hline
\end{tabular}

The staining intensities of PDCD4 and $\beta$-cateinin in the nucleus, cytoplasm and membrane were estimated as follows. PDCD4 in the nucleus: 5 , very strong, normal cell level; 4 , frequent and strong; 3 , frequent but weak; 2 , less frequent and weak; 1 , negative, staining level with nonimmune serum; PDCD4 in the cytoplasm: 4, strong; 3, moderate; 2, weak; 1, negative, staining level with non-immune serum; expression of $\beta$-catenin: 4, strong; 3 , moderate; 2 , weak; 1 , negative, staining level with non-immune serum. Control, normal tissue.

for $10 \mathrm{~min}$. An aliquot (10 $\mu \mathrm{g}$ protein) of each sample was separated by SDS-polyacrylamide gel electrophoresis and transblotted onto a Sequi-Blot PVDF membrane (Bio-Rad, Hercules, CA). After blocking with $5 \%$ skim milk at $4^{\circ} \mathrm{C}$ overnight, the membrane was incubated with a primary antibody followed by a horseradish peroxidase-conjugated anti-rabbit IgG secondary antibody. Specific bands were visualized using an ECL kit (Amersham, Buckinghamshire, UK) according to the manufacturer's protocol. The intensities of the bands were determined using Image $\mathrm{J}$ version 1.41 o software $(\mathrm{NIH}$, Bethesda, MD).

Real-time RT-PCR. Total RNA was extracted using an Isogen kit (Nippon Gene, Tokyo, Japan) according to the manufacturer's protocol. Quantitative analyses were performed using a real-time RT-PCR kit (Applied Biosystems, Foster City, CA) according to the manufacturer's protocol. The PDCD4 primer HS00205438_ml (Applied Biosystems) was used together with the GAPDH primer HS99999905_ml (Applied Biosystems) as a control.

Statistical analysis. Statistical summarization and analysis of the correlation between PDCD 4 and $\beta$-catenin were performed with Dr. SPSS II software (SPSS Japan Co., Ltd., Tokyo, Japan). Differences were considered significant at $\mathrm{P}<0.05$.

\section{Results}

Clinical characteristics of the subjects. The clinicopathological characteristics of the 21 subjects enrolled in this study are summarized in Table I. The pathological grade, as the degree of differentiation of the gastric adenocarcinoma, was well in seven subjects, moderate in five subjects, poor in seven subjects and signet ring cell in two subjects.

Expression patterns of PDCD4 in gastric adenocarcinoma. The pathological features of the samples are summarized in Table II. PDCD4 was strongly expressed in the nuclei with weak expression in the cytoplasm in the normal gastric tissues (Fig. 1Bb). PDCD4-positive cells were localized in the deep mucosae overlapping with the PCNA-positive cell area in the normal tissues (Fig. 1Bb). In the gastric adenocarcinoma tissues, PDCD4 protein was localized mostly in the cytoplasm and less frequently and more weakly in the nuclei, compared with the normal tissues (Fig. 1). A comparison of the staining patterns in the differentiated types of carcinoma tissues with those in the poorly differentiated tissues revealed that the frequencies of nuclear staining of grade 2 or more were highest in the well-differentiated tissues $(6 / 7$, $86 \%$ ) and decreased according to the differentiation grade $(3 / 5,60 \%$ and $3 / 7,43 \%$ for moderately and poorly differenti- 
A

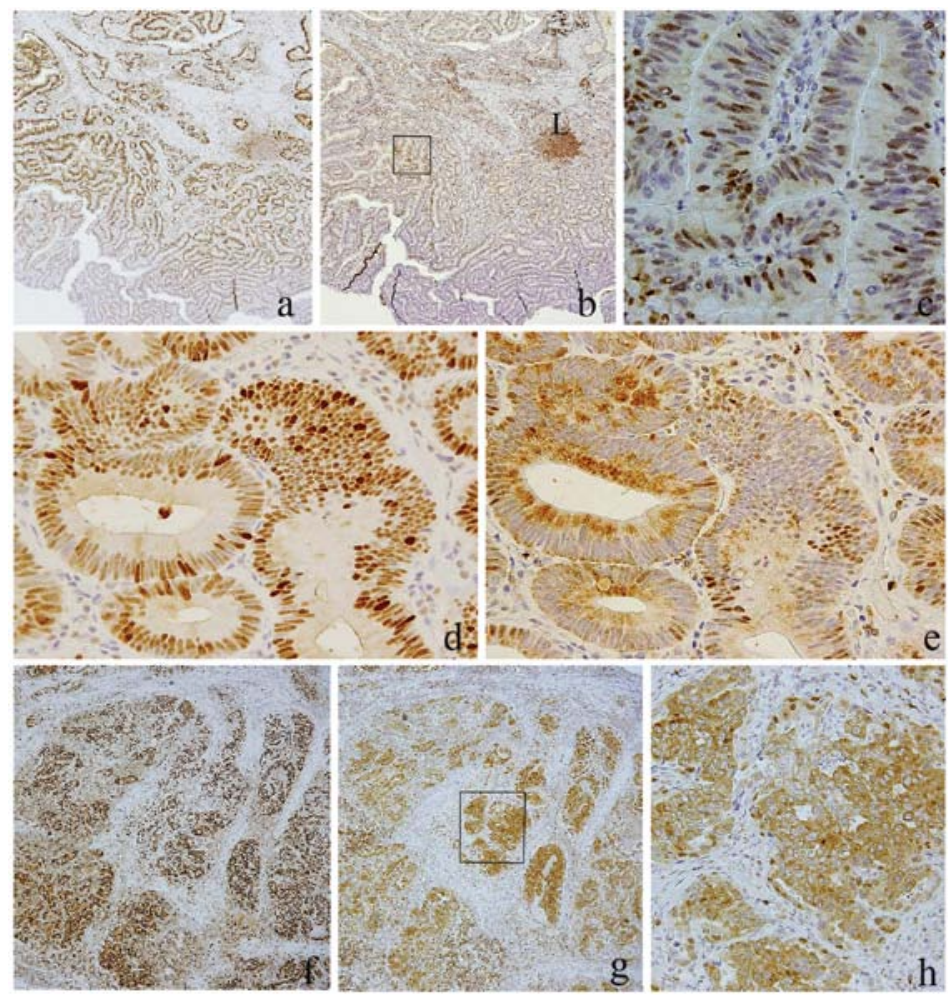

B
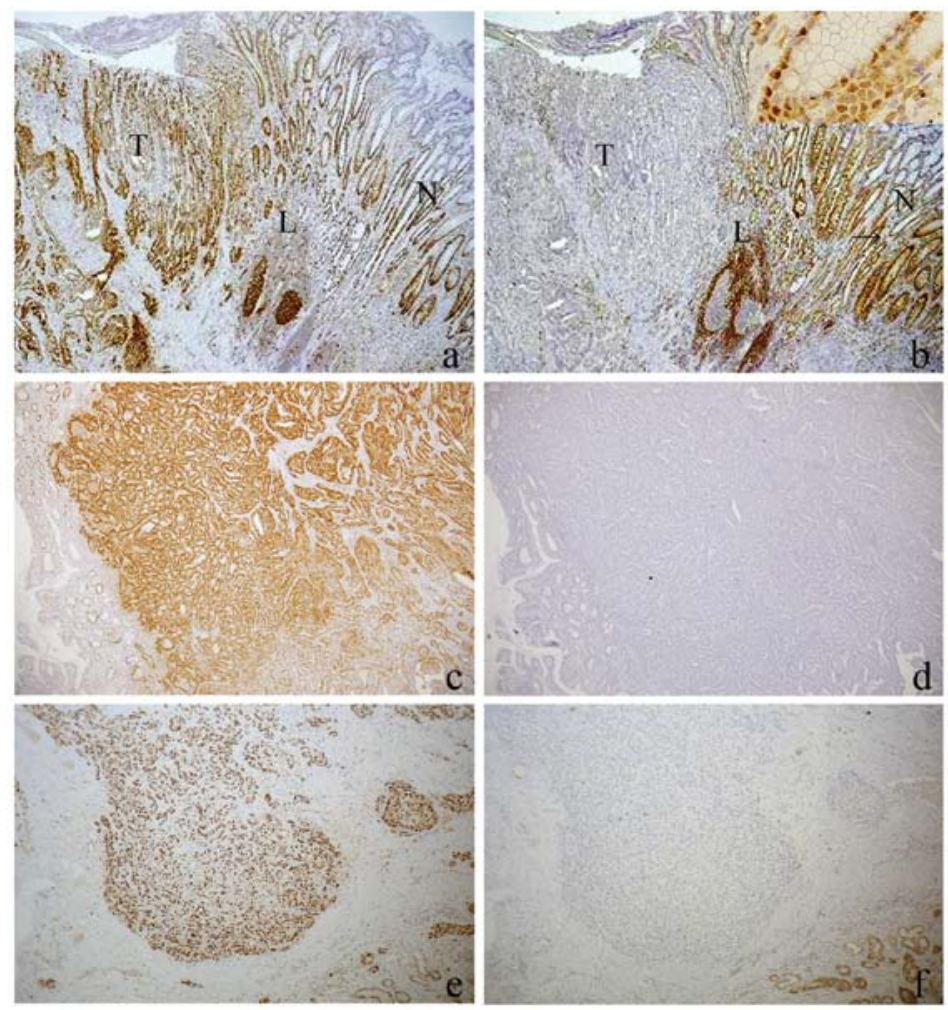

Figure 1. Expression patterns of PDCD4 in adenocarcinoma tissues. (A) Positive expression patterns of PDCD4. Serial sections of a well differentiated gastric carcinoma tissue specimen (sample 2 in Table II) were stained with anti-PCNA (a) and anti-PDCD4 (b) antibodies. Original magnification, x40. (c) Higher magnification image of the field marked with a square in panel b. PDCD4 is still localized in the nuclei of the tumor cells but less frequently compared with the normal tissues. Original magnification, $x 400$. Serial sections of a moderately differentiated carcinoma tissue specimen (sample 8 in Table II) were stained with anti-PCNA (d) and anti-PDCD4 (e) antibodies. The cytoplasm is well stained and some nuclei are also PDCD4-positive. Original magnification, x400. Serial sections of a poorly differentiated carcinoma tissue specimen (sample 13 in Table II) were stained with anti-PCNA (f) and anti-PDCD4 (g) antibodies. (h) Higher magnification image of the field marked with a square in panel g. PDCD4 protein is localized mostly in the cytoplasm and occasionally in the nuclei Original magnification, f and $\mathrm{g}, \mathrm{x} 40 ; \mathrm{h}, \mathrm{x} 200$. L, lymphoid nodule. (B) Poor expression patterns of PDCD4. Serial sections of sample 7 (Table II) were stained with anti-PCNA (a) and anti-PDCD4 (b) antibodies. Insert in panel b, higher magnification image of the area indicated by an arrow. N, normal cell area; T, tumor cell area; L, lymphoid nodules. It should be noted that the inside PCNA-positive cells are PDCD4-negative while the outside PCNA-negative cells are PDCD4-positive in the nodules and that PDCD4 is localized in the cytoplasm of lymphocytes. Serial sections of sample 11 (Table II) stained with anti-PCNA (c) and anti-PDCD4 (d) antibodies. Serial sections of a poorly differentiated carcinoma tissue specimen (sample 16 in Table II) stained with anti-PCNA (e) and anti-PDCD4 (f) antibodies. Original magnification, $\mathrm{x} 40$. 

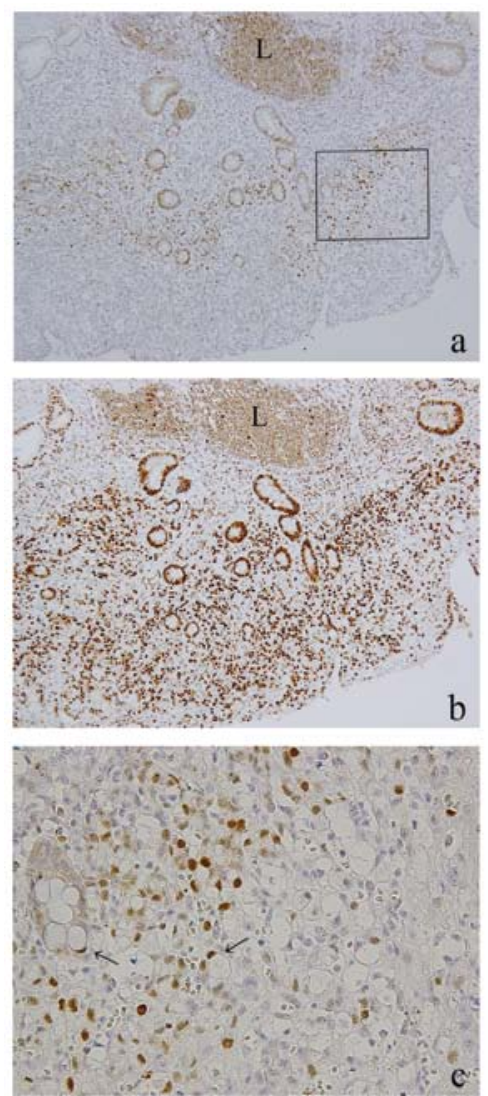

Figure 2. Expression patterns of PDCD4 in a gastric signet-ring cell carcinoma. Immunohistological images of a gastric signet ring carcinoma stained with anti-PDCD4 (a) and anti-PCNA (b) antibodies. (c) Higher magnification image of the field marked with a square in panel a. The arrows show PDCD4-positive nuclei in the signet ring cells. The PDCD4-positive nuclei are localized as a belt in the middle of the epithelium (a). L, lymphoid nodule. Original magnification, a and b, x100; c, x400. ated cancer tissues, respectively). However, the staining in the cytoplasm was similar for all differentiation grades, or somewhat increased in the poorly differentiated grade (Table II).

Expression patterns of PDCD4 in gastric signet ring cell carcinoma. We examined two samples of signet ring cell carcinoma tissues from two patients. The staining patterns of PDCD4 were similar in both carcinoma tissue specimens, but very different from the patterns in the adenocarcinoma tissues described above. PDCD4-positive nuclei were localized as a belt in the middle of the epithelial layer in the signet ring cell carcinoma tissues (Fig. 2a and b). The cell nuclei of the signet ring cells were often PDCD4-positive, while the cytoplasm was poorly stained (Fig. 2c). Invasion was not observed in either tissue specimen.

PDCD4 expression is correlated with $\beta$-catenin expression in gastric adenocarcinoma cells. It has been shown that PDCD4 suppression decreases E-cadherin expression followed by release of $\beta$-catenin from the membrane, thereby activating c-myc through the transcription factor $\beta$-catenin/Tcf in colon cancer cell line $(35,36)$. To examine the correlation between PDCD4 and $\beta$-catenin expression, sections of the gastric carcinoma tissues were stained with an anti- $\beta$-catenin antibody. $\beta$-catenin was localized in the cell membrane of normal gastric cells (Fig. 3a), consistent with a previous study (40) and PDCD4 was strongly expressed in the nuclei of these cells (Fig. 3b). The staining patterns of $\beta$-catenin in the carcinoma tissues were mostly in the cytoplasm, but occasionally included cell membrane staining (Fig. 3c and e; Table II). Five of 12 well/moderately and two of seven poorly differentiated carcinoma tissues showed $\beta$-catenin staining in the cell membrane, and six of the seven samples with $\beta$-catenin staining in the
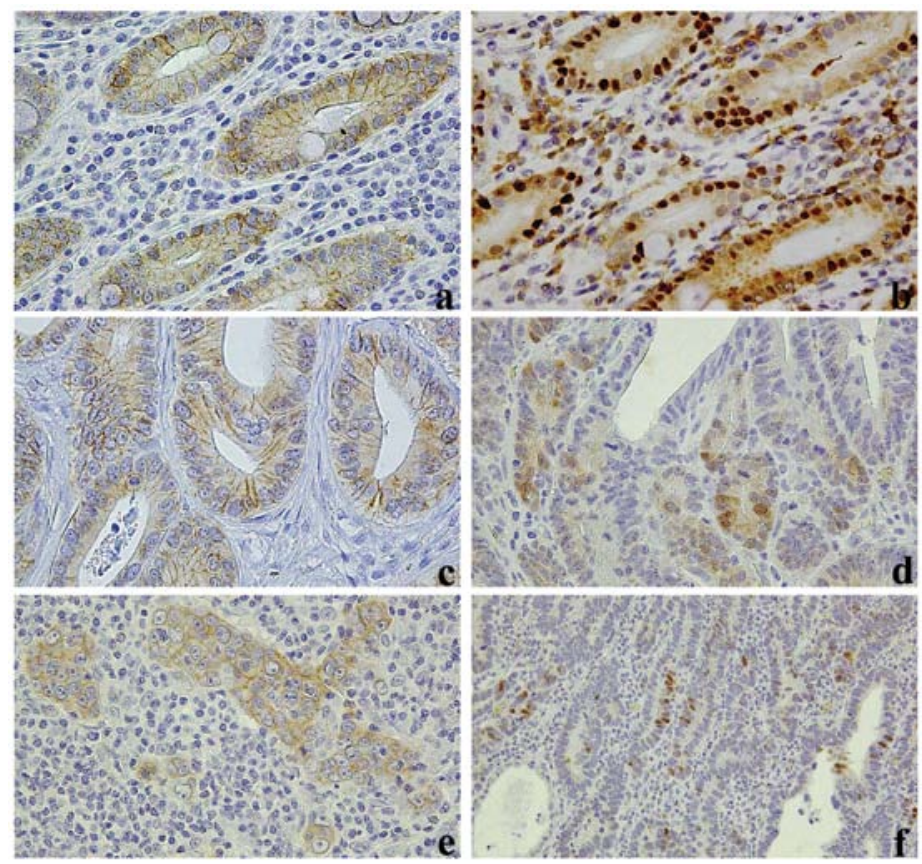

Figure 3. Immunohistological staining patterns of gastric adenocarcinoma tissues with an anti- $\beta$-catenin antibody. (a) Normal gastric tissue stained with an anti- $\beta$-catenin antibody. $\beta$-catenin is mainly localized in the cell membrane. (b) Serial section to that shown in panel a stained with an anti-PDCD4 antibody. Samples 1 (c), 4 (d), 17 (e) and 9 (f) in Table II were stained with an anti- $\beta$-catenin antibody. The membranous $\beta$-catenin-positive specimens shown in panels $\mathrm{c}$ and e, an well differentiated adenocarcinoma (sample 1) and a poorly differentiated adenocarcinoma (sample 17) were nuclear PDCD4-positive as shown in Table II. Original magnification, x400. 


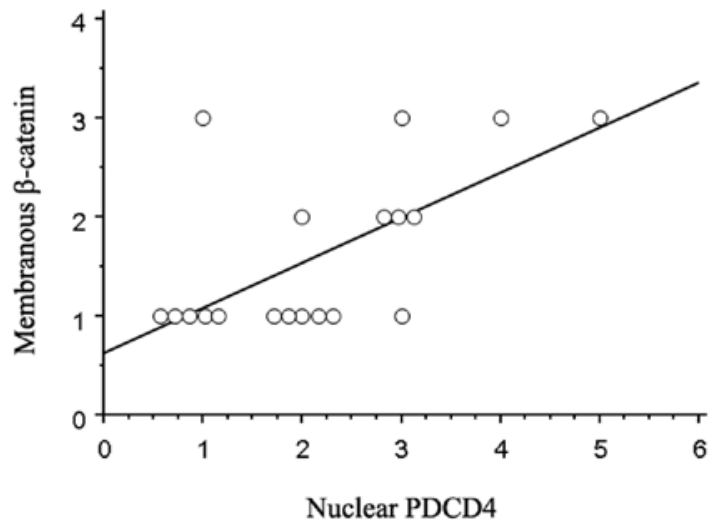

Figure 4. Correlation of nuclear PDCD4 expression and membranous $\beta$-catenin in gastric adenocarcinoma tissues. Data for 19 adenocarcinoma tissues and a normal tissue (Table II) were used for the correlation analysis. $\mathrm{r}=0.618, \mathrm{p}=0.004,95 \% \mathrm{CI}=0.227-0.837$.

cell membrane contained PDCD4-positive nuclei, with the exception of sample number 7 (Table II). In addition, the correlation between the expression grades of PDCD4 in the nuclei and $\beta$-catenin in the membrane was statistically significant $(r=0.618, p=0.004,95 \%$ CI=0.227-0.837; Fig. 4). Nuclear staining of $\beta$-catenin (Fig. 3d and $\mathrm{f}$ ) was observed in two of seven well differentiated and two of five moderately differentiated carcinoma tissues, but not in the poorly differentiated tissues (Table II).

To further investigate the correlation between PDCD4 and $\beta$-catenin, the two proteins were analyzed in gastric carcinoma cell lines by Western blotting together with E-cadherin, which is the binding partner of $\beta$-catenin. Akt and ErK were also examined, because they function to control the PDCD4 levels by participating in the degradation of PDCD4 protein $(11,12)$. Among them, only $\beta$-catenin expression was significantly correlated with PDCD4 expression (Fig. 5B-D).

PDCD4 expression is mostly controlled at the transcription level in the gastric carcinoma cell lines. The PDCD4 protein levels were generally suppressed in tumor cells compared with the corresponding normal cells. However, the mechanisms of the protein suppression varied between suppression at the transcription level and/or the post-transcription levels depending on the cell types or species involved. As shown in Fig. 5A and C, the PDCD4 protein and mRNA levels were both suppressed in gastric carcinoma cell lines compared with the normal gastric tissues and the PDCD4 protein levels were well correlated with the mRNA levels (Fig. 5D). These findings indicate that the PDCD4 levels may be mainly controlled at the transcription level in the gastric carcinoma cell lines.

\section{Discussion}

In the present study, we observed that PDCD4 protein was mostly localized in the nuclei with much smaller amounts in the cytoplasm in the normal gastric cells. The expression in the nuclei was largely suppressed, while that in the cytoplasm was retained or somewhat increased in the gastric carcinoma cells, indicating that loss of PDCD4 protein from the nuclei may be important in carcinogenesis of gastric cells. Fassen et al (41) recently reported that loss of nuclear PDCD4 was inversely correlated with the miR-21 level in colon carcinogenesis. In gastric carcinomas, suppression of PDCD4 was shown to be correlated with clinicopathological parameters such as size,
A. RT-PCR of PDCD4

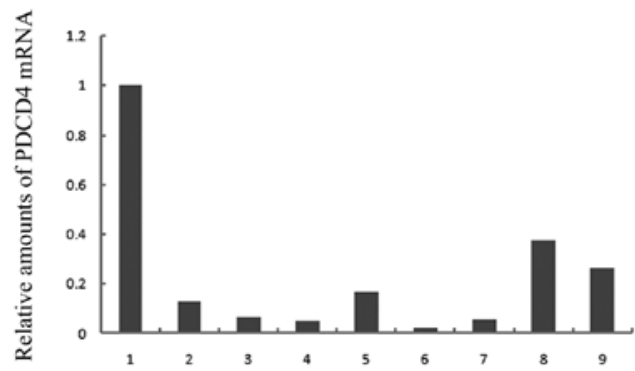

C. Western blot analysis of PDCD4

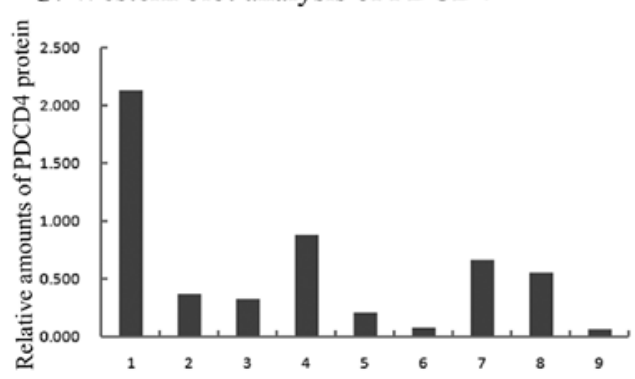

B. Western blot

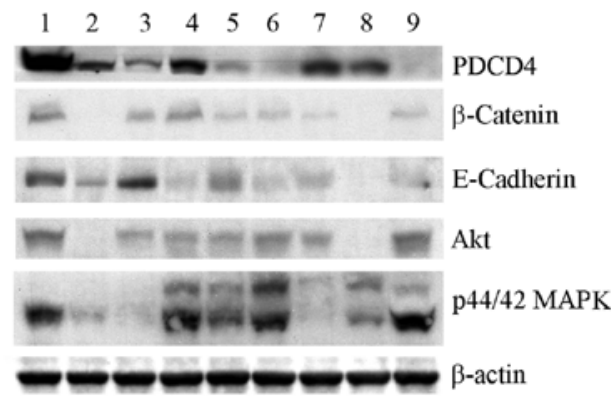

D. Correlation of PDCD4 expression with that of others described below

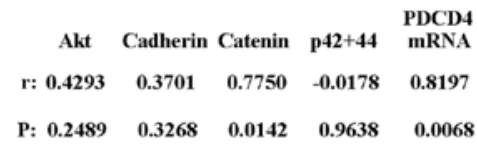

Figure 5. PDCD4 protein levels are correlated with PDCD4 mRNA and $\beta$-catenin protein levels in gastric carcinoma cell lines. (A) PDCD4 mRNA levels in the cell lines determined by quantitative RT-PCR analyses. The relative mRNA amounts are shown when the amount in the normal tissue is set at 1 . (B) Western blot analysis of the cell lines. (C) PDCD4 protein levels in the cell lines evaluated by the Western blot analysis shown in panel B. The relative protein amounts are shown when the amount in the normal tissue is set at 1. (D) Correlations of the PDCD4 protein levels with other factors. Statistical data were obtained from the data shown in panels A-C. Normal gastric tissue (1) and cell lines MKN1 (2), MKN7 (3), MKN28 (4), MKN45 (5), MKN74 (6), KATOIII (7), HSC45 (8) and HSC57 (9) were analyzed. 
depth, invasion, metastasis, advanced stage and poor clinical prognosis (38).

The PDCD4 is controlled at the levels of transcription, translation and degradation of the protein. PDCD4 translation was inhibited by miR-21, the expression of which was up-regulated in tumor cells (reviewed in refs. 21 and 22). The degradation of the protein was stimulated through activation of the Akt-mTOR-S6K signaling pathway and the MAP kinase pathway $(11,12,14)$. It was reported that the PDCD4 protein and mRNA levels were often not correlated in human tumors $(16,42)$. The loss of PDCD4 expression was associated with methylation of PDCD4 5' $\mathrm{CpG}$ islands in gliomas (42). In contrast, we have observed that the mRNA levels in hepatoma tissues were not suppressed compared with the levels in normal tissues (Ozaki et al unpublished data), despite suppression of the protein levels (13). The PDCD4 protein and mRNA levels were correlated in the gastric cancer cell lines examined (Fig. 5), and the mRNA levels have been shown to be down-regulated in gastric tumor tissues compared with normal tissues (38). These observations indicate that the PDCD4 5' $\mathrm{CpG}$ islands may be overmethylated and that PDCD4 expression is mainly regulated at the transcription level in gastric cancer cells. In addition, PDCD4 expression may be controlled at the translation level, because the miR-21 levels were increased, with an inverse correlation with the PDCD4 mRNA levels in gastric carcinoma cells (38).

PDCD4 knockdown decreased E-cadherin expression via up-regulation of the E-cadherin suppressor Snail, induced the release of $\beta$-catenin from the cell membrane and activated $\beta$-catenin/Tcf-dependent transcription of genes such as cMyc and U-PAR, resulting in invasion of colon cancer cells $(35,36)$. Free $\beta$-catenin is rapidly phosphorylated by glycogen synthase kinase-3b (GSK-3b) in the complex of adenomatous polyposis coli (APC)-axin-GSK-3b-casein kinase (CK1) and is degraded by the proteasome pathway (43). The phosphorylation levels of GSK-3b at $S^{9}$ were closely linked to gastric carcinogenesis and subsequent progression (44). It was shown that gastrin 17 stimulated nuclear translocation of $\beta$-catenin and Snail expression through inhibition of GSK-3b by phosphorylation at $\mathrm{S}^{9}$, resulting in promotion of migration in gastric cancers (45). Grabsch et al (40) investigated the expression patterns of $\beta$-catenin in 401 gastric carcinomas, and observed that $\beta$-catenin was expressed in the cell membrane of normal gastric mucosae, and that the membranous expression was reduced in the majority of gastric cancers. They showed different staining patterns in the membrane, cytoplasm and/or nuclei, and did not observe any significant correlations between the staining patterns and histopathological or clinicopathological parameters, as well as blood and lymphatic vessel invasions. However, another study described that the expression of E-cadherin and $\beta$-catenin was reduced in 43.5 and $42.6 \%$ of samples, respectively, and that their reduced expression was correlated with the differentiation grade in early gastric cancer (46). In patients with advanced gastric cancer, it was reported that $\beta$-catenin expression was correlated with invasion and metastasis, while E-cadherin expression was not (47).

The present data revealed that the localization of $\beta$-catenin in the cell membrane was associated with the localization of PDCD4 in the nuclei in gastric cancer tissues. These findings may indicate that PDCD4 controls the localization of $\beta$-catenin in gastric cancer cells, similarly to colon cancer. However, PDCD4 expression was correlated with $\beta$-catenin expression, while E-cadherin expression was not correlated with either PDCD4 or $\beta$-catenin expression in gastric carcinoma cell lines. Therefore, the control mechanisms of E-cadherin and $\beta$-catenin by PDCD4 may be not simple in the carcinogenesis of gastric cells. More investigations are necessary in the future.

Wang et al $(48,49)$ demonstrated that PDCD4 mediates the sensitivity of gastric cancer cells to tumor necrosis factorrelated apoptosis-induced ligand (TRAIL)-induced apoptosis via down-regulation of FADD-like interleukin-1 $\beta$-converting enzyme (FLICE) inhibitor (FLIP).

In conclusion, PDCD4 was mostly localized in the nuclei in normal gastric cells and the nuclear PDCD4 was decreased in gastric carcinoma tissues. The loss of nuclear PDCD4 was correlated with the loss of membranous $\beta$-catenin, indicating that nuclear PDCD4 may function to suppress gastric carcinogenesis at least partly by inhibiting the activation of $\beta$-catenin as the mechanism of colon carcinogenesis.

\section{References}

1. Matsuhashi S, Yoshinaga H, Yatsuki H, Tsugita A and Hori K: Isolation of a novel gene from a human cell line with $\operatorname{Pr}-28 \mathrm{MAb}$ which recognizes a nuclear antigen involved in the cell cycle. Res Commun Biochem Cell Mol Biol 1: 109-120, 1997.

2. Yoshinaga H, Matsuhashi S, Fujiyama $C$ and Masaki Z: Novel human PDCD4 (H731) gene expressed in proliferative cells is expressed in the small duct epithelial cells of the breast as revealed by an anti-H731 antibody. Pathol Int 49: 1067-1077, 1999.

3. Soejima H, Miyoshi O, Yoshinaga H, Masaki Z, Ozaki O, Kajihara S, Niikawa N, Matsuhashi S and Mukai T: Assignment of the programmed cell death 4 gene (PDCD4) to human chromosome band 10q24 by in situ hybridization. Cytogenet Cell Genet 87: 113-114, 1999.

4. Shibahara K, Asano M, Ishida Y, Aoki T, Koike T and Honjo T: Isolation of a novel mouse gene MA-3 that is induced upon programmed cell death. Gene 166: 297-301, 1995.

5. Onishi Y, Hashimoto S and Kizaki H: Cloning of the TIS gene suppressed by topoisomerase inhibitors. Gene 215: 453-459, 1998.

6. Schlichter U, Burk O, Worpenberg S and Klempnauer KH: The chicken Pdcd4 gene is regulated by v-Myb. Oncogene 20: 231-239, 2001.

7. Schlichter U,Kattmann D, Appl H, Miethe J, Brehmer-Fastnacht A and Klempnauer KH: Identification of the myb-inducible promoter of the chicken Pdcd4 gene. Biochem Biophys Acta 1520: 99-104, 2001.

8. Goke A, Goke R, Knolle A, Trusheim H, Schmidt H, Wilmen A, Carmody R, Goke B and Chen YH: DUG is a novel homologue of translation initiation factor $4 \mathrm{G}$ that binds eIF4A. Biochem Biophys Res Commun: 297: 78-82, 2002.

9. Azzoni L, Zatsepnia O, Abebe B, Bennett IM, Kanakaraj P and Perussia BJ: Differential transcriptional regulation of CD161 and a novel gene, 197/15a by IL-2, IL-15 and IL-12 in NK and T cells. J Immunol 161: 3493-3500, 1998.

10. Afonia O, Juste D, Das S, Matsuhashi S and Samuels HH: Induction of PDCD4 tumor suppressor gene expression by RAR agonists, antiestrogen and HER-2/neu antagonist in breast cancer cells. Evidence for a role in apoptosis. Oncogene 23: 8135-8145, 2004.

11. Schmid T, Jansen AP, Baker AR, Hegamyer G, Hagen JP and Colburn NH: Translation inhibitor Pdcd4 is targeted for degradation during tumor promotion. Cancer Res 68: 1254-1260, 2008.

12. Nakashima M, Hamajima H, Xia J, Iwane S, Kawaguchi Y, Eguchi Y, Mizuta T, Fujimoto K, Ozaki I and Matsuhashi S: Regulation of tumor suppressor PDCD4 by novel protein kinase C isoforms. Biochim Biophys Acta 1803: 1020-1027, 2010. 
13. Zhang H, Ozaki I, Mizuta T, Hamajima H, Yasutake T, Eguchi Y, Ideguchi H, Yamamoto $\mathrm{K}$ and Matsuhashi S: Involvement of programmed cell death 4 in transforming growth factor- $\beta 1$ induced apoptosis in human hepatocellular carcinoma. Oncogene 25: 6101-6112, 2006.

14. Dorrello NV, Peschiaroli A, Guardavaccaro D, Colburn NH, Sherman NE and Pagano M: S6K1- and betaTRCP-mediated degradation of PDCD4 promotes protein translation and cell growth. Science 314: 467-471, 2006.

15. Matsuhashi S, Narisawa Y, Ozaki I and Mizuta T: Expression patterns of programmed cell death 4 protein in normal skin and some representative skin lesions. Exp Dermatol 16: 179-184, 2007.

16. Chen Y, Knosel T, Kristiansen G, Pietas A, Garber ME, Matsuhashi S, Ozaki I and Petersen I: Loss of PDCD4 expression in human lung cancer correlates with tumour progression and prognosis. J Pathol 200: 640-646, 2003.

17. Ma G, Guo KJ, Zhang H, Ozaki I, Matsuhashi S, Zheng XY and Dong M: Expression of programmed cell death 4 and its clinicopathological significance in human pancreatic cancer. Zhongguo Yi Xue Ke Xue Yuan Xue Bao 27: 597-600, 2005.

18. Lee S, Bang S, Song K and Lee I: Differential expression in normal-adenoma-carcinoma sequence suggests complex molecular carcinogenesis in colon. Oncol Rep 16: 747-754, 2006.

19. Wen YH, Shi X, Chiriboga L, Matsuhashi S, Yee $\mathrm{H}$ and Afonia O: Alterations in the expression of PDCD4 in ductal carcinoma of the breast. Oncol Rep 18: 1387-1393, 2007.

20. Gao F, Zhang P, Zhou C, Li J, Wang Q, Zhu F, Ma C, Sun W and Zhang L: Frequent loss of PDCD4 expression in human glioma: possible role in the tumorigenesis of glioma. Oncol Rep 17: 123-128, 2007.

21. Allgayer $\mathrm{H}$ : PDCD4, a colon cancer prognostic that is regulated by a microRNA. Crit Rev Oncol Hematol 73: 185-191, 2010.

22. Young MR, Santhanam AN, Yoshikawa N and Colburn NH: Have tumor suppressor PDCD4 and its counteragent oncogenic miR-21 gone rogue? Mol Interv 10: 76-79, 2010.

23. Aravind L and Koonin EV: Eukaryote-specific domains in translation initiation factors: inplications for translation regulation and evolution of the translation system. Genome Res 10 1172-1184, 2000.

24. Yang HS, Jansen AP, Komar AA, Zheng X, Merrick WC, Costes S, Lockett SJ, Sonenberg N and Colburn NH: The transformation suppressor Pdcd4 is a novel eukaryotic translation initiation factor $4 \mathrm{~A}$ binding protein that inhibits translation. Mol Cell Biol 23: 26-37, 2003.

25. Yang HS, Cho MH, Zakowicz H, Hegamyer G, Sonenberg $\mathrm{N}$ and Colburn NH: A novel function of the MA-3 domains in transformation and translation suppressor Pdcd4 is essential for its binding to eukaryotic translation initiation factor 4A. Mol Cell Biol 24: 3894-3906, 2004.

26. LaRonde-LeBlanc N, Santhanam AN, Baker AR, Wlodawer A and Colburn NH: Structural basis for inhibition of translation by the tumor suppressor Pdcd4. Mol Cell Biol 27: 147-156, 2007.

27. Suzuki C, Garces RG, Edmonds KA, Hiller S, Hyberts SG, Marintchev A and Wagner G: PDCD4 inhibits translation initiation by binding to eIF4A using both its MA3 domains. Proc Natl Acad Sci USA 105: 3274-3279, 2008.

28. Cmarik JL, Min H, Hegamyer G, Zhan S, Kulesz-Martin M, Yoshinaga H, Matsuhashi S and Colburn NH: Differentially expressed protein Pdcd4 inhibits tumor pormoter-induced neoplastic transformation. Proc Natl Acad Sci USA 96: 1403714042, 1999.

29. Yang HS, Jansen AP, Nair R, Shibahara K, Verma AK, Cmarik JL and Colburn NH: A novel transformation suppressor, Pdcd4, inhibits AP-1 transactivation but not NF-kappaB or ODC transactivation. Oncogene 20: 669-676, 2001.

30. Yang HS, Knies JL, Stark C and Colburn NH: Pded4 suppresses tumor phenotype in JB6 cells by inhibiting AP-1 transactivation. Oncogene 22: 3712-3720, 2003.

31. Bitomsky N, Bohm M and Klempnauer KH: Transformation suppressor protein Pdcd4 interferes with JNK-mediated phosphorylation of c-Jun and recruitment of the coactivator p300 by c-Jun. Oncogene 23: 7484-7493, 2004.
32. Yang HS, Matthews CP, Clair T, Wang Q, Baker AR, Li CC, Tan TH and Colburn NH: Tumorigenesis suppressor Pded4 down-regulates mitogen-activated protein kinase kinase kinase kinase 1 expression to suppress colon carcinoma cell invasion. Mol Cell Biol 26: 1297-1306, 2006.

33. Jansen AP, Camalier CE and Colburn NH: Epidermal expression of the translation inhibitor programmed cell death 4 suppresses tumorigenesis, Cancer Res 65: 6034-6041, 2005.

34. Hilliard A, Hilliard B, Zheng SJ, Sun H, Miwa T, Song W, Goke R and Chen YH: Translational regulation of autoimmune inflammation and lymphoma genesis by programmed cell death 4. J Immunol 177: 8095-8102, 2006.

35. Wang Q, Sun Z and Yang HS: Downregulation of tumor suppressor Pdcd4 promotes invasion and activates both betacatenin/Tcf and AP-1-dependent transcription in colon carcinoma cells. Oncogene 27: 1527-1535, 2008.

36. Wang Q, Sun ZX, Allgayer H and Yang HS: Downregulation of E-cadherin is an essential event in activating $\beta$-catenin/ Tcf-dependent transcription and expression of its target genes in Pdcd4 knockdown cells. Oncogene 29: 128-138, 2010.

37. Santhanam AN, Baker AR, Hegamyer G, Kirschmann DA and Colburn NH: Pdcd4 repression of lysyl oxidase inhibits hypoxiainduced breast cancer cell invasion. Oncogene 29: 3921-3932, 2010.

38. Motoyama K, Inoue H, Mimori K, Tanaka F, Kojima K, Uetake H, Sugihara K and Mori M: Clinocopathological and prognostic significance of PDCD4 and microRNA-21 in human gastric cancer. Int J Oncol 36: 1089-1095, 2010

39. Yanagihara K, Tanaka H, Takigahira M, Ino Y, Yamaguchi Y, Toge T, Sugano K and Hirohashi S: Establishment of two cell lines from human gastric scirrhous carcinoma that posseess the potential to metastasize spontaneously in nude mice. Cancer Sci 95: 575-582, 2004

40. Grabsch H, Takeno S, Noguchi T, Hommel G, Gabbert HE and Mueller W: Different patterns of $\beta$-catenin expression in gastric carcinomas: relationship with clinicopathological parameters and prognostic outcome. Histopathology 39: 141-149, 2001.

41. Fassan M, Pizzi M, Giacomelli L, Mescoli C, Ludwig K, Pucciarelli S and Rugge M: PDCD4 nuclear loss inversely correlates with miR-21 levels in colon carcinogenesis. Virchows Arch 458: 413-419, 2011

42. Gao F, Wang X, Zhu F, Wang Q, Zhang X, Guo C, Zhou C, Ma C, Sun W, Zhang Y, Chen YH and Zhang L: PDCD4 gene silencing in gliomas is associated with $5^{\prime} \mathrm{CpG}$ island methylation and unfavourable prognosis. J Cell Mol Med 13: 4257-4267, 2009.

43. Gregorieff A and Clevers H: Wnt signaling in the intestinal epithelium: from endoderm to cancer. Genes Dev 19: 877-890, 2005.

44. Zheng HC, Xu XY, Xia P, Yu M, Takahashi H and Takano Y: Involvement of inactive GSK3beta overexpression in tumorigenesis and progression of gastric carcinomas. Hum Pathol 41: 1255-1264, 2010.

45. Mishra P, Senthivinayagam S, Rana A and Rana B: Glycogen synthase kinase-3beta regulates Snail and beta-catenin during gastrin-induced migration of gastric cancer cells. J Mol Signal 5: 9, 2010.

46. Joo YE, Rew JS, Choi SK, Bom HS, Park CS and Kim SJ: Expression of E-cadherin and catenins in early gastric cancer. J Clin Gastroenterol 35: 35-42, 2002.

47. Czyzewska J, Guzinska-Ustymowicz K, Ustymowicz M, Pryczynicz A and Kemona A: The expression of E-cadherincatenin complex in patients with advanced gastric cancer: role in formation of metastasis. Folia Histchem Cytobiol 48: 37-45, 2010.

48. Wang W, Zhao J, Wang H, Sun Y, Peng Z, Zhou G, Fan L, Wang X, Yang S, Wang R and Fang D: Programmed cell death 4 (PDCD4) mediates the sensitivity of gastric cancer cells to TRAIL-induced apoptosis by down-regulation of FLIP expression. Exp Cell Res 316: 2456-2464, 2010.

49. Wang WQ, Zhang $\mathrm{H}$, Wang HB, Sun YG, Peng ZH, Zhou G, Yang SM, Wang RO and Fang DC: Programmed cell death4 (PDCD4) enhances the sensitivity of gastric cancer cells to TRAIL-induced apoptosis by inhibiting the PI3K/Akt signaling pathway. Mol Diagn Ther 14: 155-161, 2010. 